\title{
Crescimento de plântulas de aveia branca submetidas ao estresse salino
}

\section{Seedling growth of white oats submitted to salt stress}

\author{
André Pich Brunes ${ }^{1 *}$; Daniel Ândrei Robe Fonseca ${ }^{1}$; Cassyo de Araujo Rufino ${ }^{2}$; \\ Lizandro Ciciliano Tavares ${ }^{1}$; Lilian Madruga Tunes ${ }^{3}$; Francisco Amaral Villela ${ }^{4}$
}

\begin{abstract}
Resumo
O cultivo de aveia branca em sucessão a cultura do arroz-irrigado é uma alternativa bastante viável, principalmente devido ao seu valor agregado e por suas características restauradoras do solo, entretanto seu potencial produtivo pode ser amplamente reduzido devido à salinização dos solos, sendo de grande importância determinar a concentração salina tolerada por diferentes cultivares de aveia branca. Objetivou-se com este trabalho avaliar cultivares de aveia branca, recomendadas para o estado do Rio Grande do Sul, submetidas a diferentes concentrações salinas na fase de germinação e crescimento inicial. O delineamento experimental utilizado foi inteiramente casualizado em esquema fatorial 2 X 5 , com quatro repetições (cultivares: Barbarasul e Chiarasul, e concentração salina nos níveis: 0, 25, 50, 75 e $100 \mathrm{mM}$ de $\mathrm{NaCl}$ por litro de água). A qualidade fisiológica das sementes foi avaliada em laboratório pelos testes de germinação, primeira contagem da germinação, comprimento de parte aérea e raiz, massa seca de parte aérea e raiz. Com base nos resultados obtidos pode-se concluir que: a germinação e o crescimento das plântulas de aveia branca das cultivares Barbarasul e Chiarasul são reduzidos com o aumento da concentração de $\mathrm{NaCl}$. Além disso, a resposta é mais acentuada sobre a parte aérea do que no sistema radicular. A concentração de $100 \mathrm{mM}$ de $\mathrm{NaCl} \mathrm{L}^{-1}$ impossibilita a germinação das sementes de ambas cultivares estudadas.
\end{abstract}

Palavras-chave: Avena sativa L., qualidade fisiológica, salinidade

\begin{abstract}
The cultivation of white oat in succession to irrigated rice is considered a viable alternative, mainly because of their added value and for their restorative characteristics of the soil, though their productive potential can be reduced considerably because of the soil salinization, being very important to determine salt concentration tolerated by different white oat cultivars. The objective is to evaluate, oat cultivars recommended for the state of Rio Grande do Sul under different salt concentrations in seed germination and early growth. The experimental design was completely randomized factorial $2 \mathrm{X} 5$, with four replications, (cultivars Barbarasul and Chiarasul, salt concentration and levels 0, 25, 50,75 and $100 \mathrm{mM}$ $\mathrm{NaCl}$ per liter of water). The physiological seed quality was evaluated in the laboratory by germination, first count of germination, length of shoot and root dry weight of shoot and root. Based on the results we can conclude that: germination and seedling growth of oat cultivars and Barbarasul Chiarasul are
\end{abstract}

1 Eng $^{\text {os }} \mathrm{Agr}^{\text {os }}$, Discente de Doutorado em Ciência e Tecnologia de Sementes, Universidade Federal de Pelotas UFPEL, Pelotas, RS. E-mail: beldar_brunes@msn.com; danielfonseca30@yahoo.com.br; lizandro_cicilianotavares@yahoo.com.br

2 Licenciado em Ciências Agrícolas, Discente de Doutorado em Ciência e Tecnologia de Sementes, UFPEL, Pelotas, RS. E-mail: cassyo.araujo@yahoo.com.br

3 Enga Agr ${ }^{\mathrm{a}}$, Prof ${ }^{\mathrm{a}} \mathrm{Dr}^{\mathrm{a}}$ do Programa em Pós-Graduação em Ciência e Tecnologia de Sementes, UFPEL, Pelotas/RS. E-mail: lilianmtunes@yahoo.com.br

4 Prof. Dr. do Programa em Pós-Graduação em Ciência e Tecnologia de Sementes, UFPEL, Pelotas, RS. E-mail: francisco.villela@ ufpel.edu.br

* Autor para correspondência 
negatively affected with increasing salt concentration. In addition the response is more pronounced on the shoot than the root system. The concentration of $100 \mathrm{mM} \mathrm{NaCl} \mathrm{L}^{-1}$ impossible to seed germination of both cultivars.

Key words: Avena sativa L., quality and physiological sodium chloride

\section{Introdução}

A aveia branca (Avena sativa L.) apresenta-se como uma importante alternativa de cultivo durante o período de outono/inverno, principalmente na região sul do Brasil, sendo amplamente utilizada em sistemas de rotação de culturas. Na safra de 2010/11, foram semeados cerca de 154 mil hectares de aveia branca, obtendo-se uma produção de 379 mil toneladas (CONAB, 2012). Essa espécie é utilizada na alimentação humana, pelo teor de proteínas de qualidade e fibras solúveis, e na alimentação animal, como forragem verde, feno, silagem e na composição da ração (CECCON; GRASSI FILHO; BICUDO, 2004). Apresenta-se como uma importante alternativa para participar do sistema de sucessão de culturas, devido as suas propriedades restauradoras do solo, tendo papel fundamental em sistemas de semeadura direta (TUNES et al., 2008).

Dentre os fatores que podem vir a limitar a produtividade da cultura destaca-se a salinização dos solos de cultivo. A salinidade é um dos estresses abióticos mais importantes, sendo amplamente distribuídos em áreas irrigadas e não irrigadas no mundo. Solos contaminados com sais (condutividade elétrica $>4 \mathrm{dS} \mathrm{m}^{-1}$ ou $40 \mathrm{mM}$ $\mathrm{NaCl}$ ou potencial osmótico $<0,117 \mathrm{MPa}$ ) são definidos como solos salinos, os quais podem afetar diretamente o crescimento e o desenvolvimento das plantas no estádio vegetativo, período que precede a fase reprodutiva, especialmente nas espécies cultivadas (ASHRAF, 2009).

Muitos dos solos da região sul, principalmente nas áreas de cultivo orizícola do Rio Grande do Sul apresentam alto teor salino e também mananciais hídricos que se ligam ao Oceano Atlântico, comumente em épocas de baixa precipitação pluvial (MARCOLIN et al., 2005). Sendo este um fator que pode vir a ser limitante ao cultivo da aveia em sucessão ao cultivo do arroz, visto que o efeito negativo da salinidade para trigo, milho, beterraba, alfafa, cevada e aveia foram constatados em experimentos conduzidos por Harris no início do século vinte, posteriormente citados por outros autores (CAMPOS e ASSUNÇÃO, 1990) sendo comprovado efeito negativo também para outras espécies, como soja (SANTOS et al., 1992), algodão (FURTADO et al., 2007), pinhão-manso (ANDRÉO-SOUZA et al., 2010), niger (GORDIN et al., 2012), entre outras, ressaltando a importância de determinar os níveis de concentração salina tolerados pela cultura, bem como identificar cultivares mais tolerantes.

Neste contexto, o objetivo deste trabalho foi avaliar a qualidade fisiológica de sementes de cultivares de aveia branca recomendadas para o estado do Rio Grande do Sul, quando submetidas a diferentes concentrações salinas na fase de germinação e crescimento inicial.

\section{Material e Métodos}

O experimento foi desenvolvido no Laboratório Didático de Análise de Sementes da Universidade Federal de Pelotas. Foram utilizadas as cultivares: Barbarasul e Chiarasul e a concentração salina, com os seguintes níveis: $0,25,50,75$ e $100 \mathrm{mM}$ de $\mathrm{NaCl}$ por litro de água, obtidos através de diluições de $\mathrm{NaCl}$ em água destilada.

A qualidade fisiológica das sementes foi avaliada pelos testes de: Germinação: realizado com quatro repetições de 50 sementes, postas para germinar sobre duas folhas de papel-toalha (papel germitest), umedecida com água destilada (nível zero) e com solução salina nos referidos níveis de salinidade em quantidade equivalente a 2,5 vezes o peso seco do papel. Em seguida foram confeccionados rolos 
de papel, mantidos em germinador à temperatura constante de $20^{\circ} \mathrm{C}$ (BRASIL, 2009). A avaliação foi realizada aos 10 dias seguindo os padrões estabelecidos para a cultura da aveia nas Regras para Análise de Sementes, e os resultados expressos em porcentagem de plântulas normais. Primeira contagem da germinação: foi efetuada aos cinco dias por ocasião do teste de germinação sendo retiradas as plântulas normais. Comprimento de parte aérea (CPA) e raiz (CR): realizado no quinto dias após a montagem do teste de germinação, sendo as plântulas escolhidas aleatoriamente (dez plântulas), obtidas a partir da semeadura de quatro repetições de 20 sementes, no terço superior da folha de papel do tipo germitest umedecidas 2,5 vezes o seu peso. Os rolos foram postos em germinador regulado a $20^{\circ} \mathrm{C}$, conforme determinações descritas por (NAKAGAWA, 1999). Determinou-se o comprimento total e da parte aérea das plântulas, com auxílio de régua graduada em milímetros, sendo o comprimento da raiz determinado pela subtração do comprimento total pelo comprimento da parte aérea. Os comprimentos médios total de plântulas, parte aérea e raiz, foram obtidos somandose as medidas de cada repetição e dividindo-se pelo número de plântulas avaliadas, com os resultados expressos em centímetros. Massa seca da parte aérea e de raiz: foram realizadas juntamente com o teste de comprimento de plântulas. A parte aérea e raiz foram separadas com auxílio de bisturi, colocados em sacos de papel e levados para secar em estufa com circulação a $60{ }^{\circ} \mathrm{C}$, durante 72 horas. Após esse período, as amostras foram colocadas para resfriar em dessecadores e pesadas em balança analítica com precisão de $0,0001 \mathrm{~g}$, os resultados foram expressos em mg.plântula ${ }^{-1}$ (NAKAGAWA, 1999). Foram também avaliadas a porcentagem de plântulas anormais e de sementes mortas.

O delineamento experimental utilizado foi inteiramente casualizado em esquema fatorial $2 \mathrm{X}$ 5, com quatro repetições, (cultivares: Barbarasul e Chiarasul e concentração salina nos níveis: 0, 25, 50, 75 e $100 \mathrm{mM}$ de $\mathrm{NaCl}$ por litro de água).
Os dados obtidos foram analisados quanto à sua homocedasticidade e submetidos à análise de variância e havendo significância, realizou-se comparação de médias através do teste de Tukey para o fator cultivar e os níveis de concentração salina foram analisados por regressão polinomial, todos a $5 \%$ de significância. Não havendo interação foram avaliados apenas os efeitos principais. As análises estatísticas foram executadas através do programa estatístico Winstat, versão 1.0 (MACHADO; CONCEIÇÃO, 2003).

\section{Resultados e Discussão}

Constatou-se que houve interação entre os tratamentos para a primeira contagem da germinação (PCG), germinação $(\mathrm{G})$ e plântulas anormais (PA), para as demais não houve interação sendo então analisados apenas os efeitos principais.

Na Tabela 1 encontram-se os resultados obtidos na comparação de médias entre as sementes das cultivares Barbarasul e Chiarasul, de aveia branca, dentro de cada nível de concentração salina, para primeira contagem de germinação, germinação, sementes mortas e plântulas anormais. Observase que para primeira contagem da germinação, as sementes da cultivar Barbarasul, apresentaram maior vigor ao serem submetidas ao nível zero (água destilada), até níveis de salinidade de concentração

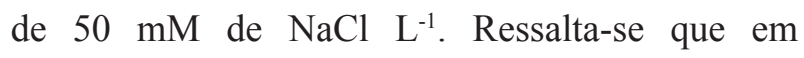
níveis superiores de concentração salina não foi constatada a presença de sementes germinadas para ambas as cultivares. Resultados semelhantes foram encontrados por Duarte et al. (2006), para sementes de trigo, em que o aumento da concentração de $\mathrm{NaCl}$ até $60 \mathrm{Mm}$ por litro reduziu a porcentagem de sementes germinadas durante a primeira contagem da germinação. No entanto, a porcentagem de sementes germinadas nessa avaliação permaneceu em $87 \%$ para as duas cultivares de trigo, podendo se inferir que as cultivares de aveia testadas neste trabalho são mais suscetíveis ao estresse salino. 
Tabela 1. Efeito da salinidade na primeira contagem de germinação (PCG), germinação (G), sementes mortas (SM) e plântulas anormais (PA) em sementes de aveia branca, cultivares Barbarasul e Chiarasul. Capão do Leão, 2012.

\begin{tabular}{|c|c|c|c|c|c|c|c|c|}
\hline \multirow{2}{*}{5} & \multicolumn{2}{|c|}{ PCG (\%) } & \multicolumn{2}{|c|}{$\mathrm{G}(\%)$} & \multicolumn{2}{|c|}{ SM (\%) } & \multicolumn{2}{|c|}{ PA $(\%)$} \\
\hline & Barbarasul & Chiarasul & Barbarasul & Chiarasul & Barbarasul & Chiarasul & Barbarasul & Chiarasul \\
\hline 0 & $-82 a^{*}$ & $63 \mathrm{~b}$ & $88 \mathrm{a}$ & $85 \mathrm{a}$ & 8 & 15 & $2 \mathrm{~b}$ & $0 \mathrm{a}$ \\
\hline 25 & $63 \mathrm{a}$ & $27 \mathrm{~b}$ & $86 a$ & $71 \mathrm{~b}$ & 10 & 15 & $5 \mathrm{~b}$ & $14 \mathrm{a}$ \\
\hline 50 & $31 \mathrm{a}$ & $4 \mathrm{~b}$ & $86 \mathrm{a}$ & $68 \mathrm{~b}$ & 8 & 21 & $7 \mathrm{a}$ & $12 \mathrm{a}$ \\
\hline 75 & $0 \mathrm{a}$ & $0 \mathrm{a}$ & $55 \mathrm{a}$ & $39 \mathrm{~b}$ & 11 & 22 & $35 \mathrm{a}$ & $40 \mathrm{a}$ \\
\hline 100 & $0 \mathrm{a}$ & $0 \mathrm{a}$ & $2 \mathrm{a}$ & $0 \mathrm{a}$ & 10 & 19 & $88 \mathrm{a}$ & $81 \mathrm{a}$ \\
\hline Média & 35 & 19 & 64 & 50 & $9 \mathrm{~b}$ & $18 \mathrm{a}$ & 27 & 31 \\
\hline C.V. (\%) & \multicolumn{2}{|c|}{18,9} & \multicolumn{2}{|c|}{10,9} & \multicolumn{2}{|c|}{19,6} & \multicolumn{2}{|c|}{16,8} \\
\hline
\end{tabular}

*Médias seguidas da mesma letra na linha em cada variável, não diferem entre si a 5\% de probabilidade de erro pelo teste de Tukey. Fonte: Elaboração dos autores.

Na germinação (Tabela 1) verifica-se se que a cultivar Barbarasul apresentou-se superior a cultivar Chiarasul ao serem submetidas a concentrações de $\mathrm{NaCl}$ entre 25 a $75 \mathrm{mM}$, não diferindo entre as cultivares na concentração de $100 \mathrm{mM}$, na qual ambas apresentaram germinação próxima de zero. Para a variável sementes mortas (SM) observou-se que, de modo geral, a cultivar Chiarasul apresentou resultado superior, sendo mais afetada pela concentração salina. $\mathrm{O}$ mesmo pode ser verificado para o número de plântulas anormais no nível de salinidade de $25 \mathrm{mM}$ de $\mathrm{NaClL}^{-1}$, pois a cultivar Chiarasul apresentou resultado superior em relação à cultivar Barbarasul, para as demais concentrações estudadas não ocorreu diferença. Em estudo com sementes de arroz expostas a meios salinos, Almeida et al. (2001) concluíram que a primeira contagem da germinação e o crescimento das plântulas de arroz são afetados negativamente pelo cloreto de sódio, concordando com os resultados encontrados para aveia neste trabalho.

Tabela 2. Efeito da salinidade no comprimento da parte aérea (CPA) e de raiz (CR), fitomassa seca da parte aérea (FSPA) e de raiz (FSR) em plântulas de aveia branca. Capão do Leão, 2012.

\begin{tabular}{|c|c|c|c|c|c|c|c|c|}
\hline \multirow{2}{*}{$\begin{array}{l}\text { Concentração } \\
\left(\mathrm{mM} \mathrm{L}^{-1}\right)\end{array}$} & \multicolumn{2}{|c|}{$\mathrm{CPA}(\mathrm{cm})$} & \multicolumn{2}{|c|}{$\mathrm{CR}(\mathrm{cm})$} & \multicolumn{2}{|c|}{ FSPA (mg) } & \multicolumn{2}{|c|}{ FSR (mg) } \\
\hline & Barbarasul & Chiarasul & Barbarasul & Chiarasul & Barbarasul & Chiarasul & Barbarasul & Chiarasul \\
\hline 0 & 16,6 & 14,1 & 11,5 & 11,7 & 63,0 & 64,9 & 37,2 & 33,7 \\
\hline 25 & 14,1 & 11,7 & 7,0 & 9,1 & 68,4 & 68,5 & 33,7 & 35,1 \\
\hline 50 & 10,1 & 7,5 & 5,5 & 6,4 & 62,9 & 56,6 & 32,9 & 26,5 \\
\hline 75 & 5,9 & 5,1 & 4,3 & 4,7 & 54,0 & 47,0 & 26,9 & 24,2 \\
\hline 100 & 3,1 & 3,0 & 2,5 & 2,7 & 27,9 & 33,3 & 16,1 & 15,7 \\
\hline Média & $10,0 \mathrm{a}$ & $8,3 \mathrm{~b}$ & $6,2 \mathrm{~b}$ & $6,9 \mathrm{a}$ & $55,2 \mathrm{a}$ & $54,0 \mathrm{a}$ & $29,4 \mathrm{a}$ & $27,0 \mathrm{a}$ \\
\hline CV $(\%)$ & \multicolumn{2}{|c|}{15,3} & \multicolumn{2}{|c|}{13,3} & \multicolumn{2}{|c|}{17,6} & \multicolumn{2}{|c|}{17,1} \\
\hline
\end{tabular}

* Médias seguidas da mesma letra na linha em cada variável, não diferem entre si a $5 \%$ de probabilidade de erro pelo teste de Tukey. Fonte: Elaboração dos autores. 
Não houve interação entre cultivar e concentração de $\mathrm{NaCl}$ para comprimento de parte aérea e raiz, bem como para fitomassa seca da parte aérea e raiz (Tabela 2), sendo então comparadas as médias gerais entre as duas cultivares. Verificou-se que as plântulas da cultivar Barbarasul apresentaram maior comprimento da parte aérea, no entanto a cultivar Chiarasul apresentou maior comprimento de raíz. Não foi constatada diferença significativa entre a fitomassa seca, tanto de parte aérea, quanto de raiz.

Figura 1. Primeira contagem de germinação, germinação, plântulas anormais e sementes mortas oriundas de sementes de aveia branca, cultivares Barbarasul e Chiarasul, submetidas a concentrações de salinidade. Capão do Leão, 2012.
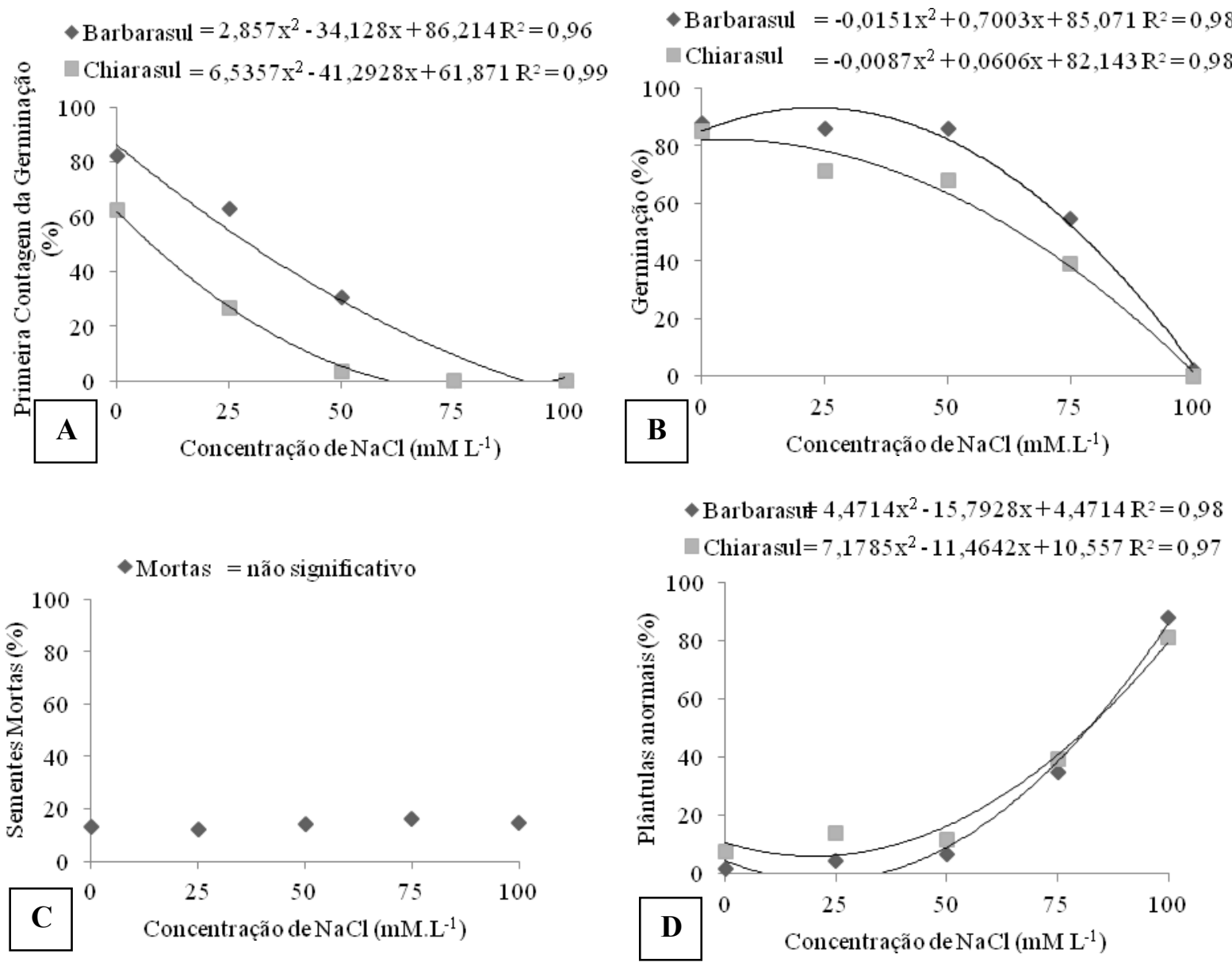

Fonte: Elaboração dos autores.

Para a primeira contagem da germinação (Figura 1A) ambas as cultivares foram afetadas negativamente pelo aumento da concentração de $\mathrm{NaCl}$, até a dose de $100 \mathrm{mM}$ de $\mathrm{NaCl} . \mathrm{L}^{-1}$, sendo que a parir da dose de $75 \mathrm{mM}$ de $\mathrm{NaCl}^{-1} \mathrm{~L}^{-1}$ não ocorreu germinação de nenhuma das cultivares. Já para porcentagem de germinação (Figura 1B) verifica-se que a cultivar Chiarasul sofreu redução no percentual em todas as doses, enquanto que a cultivar Barbarasul teve sua germinação estimulada pelo sal até a concentração de $23,2 \mathrm{mM} \mathrm{L}^{-1}$, a partir desta concentração sua germinação também foi prejudicada . Na dose de $100 \mathrm{mM}$ de NaCl.L ${ }^{-1}$ ambas as cultivares obtiveram percentual de 
germinação muito próximo a zero. Salienta-se que a inibição da germinação ocasionada pelo $\mathrm{NaCl}$ pode ser mais drástica do que a ocasionada pela solução salina do solo, como foi constatado em um estudo realizado para determinar o comportamento da germinação de sementes de arroz em meios salinos, onde se concluiu que o efeito do $\mathrm{NaCl}$ na primeira contagem da germinação é mais acentuado do que o da água salina de açude (ALMEIDA et al., 2001).
Também para sementes de milho submetidas ao estresse salino por diferentes agentes osmóticos, Conus et al. (2009), concluíram que o efeito salino do $\mathrm{NaCl}$ é maior nas características altura de planta, comprimento radicular, área foliar e massa seca de raiz em comparação aos sais de cloreto de cálcio e de potássio. De maneira geral, verifica-se que a cultivar Chiarasul apresentou maior sensibilidade ao estresse salino comparativamente a cultivar Barbarasul.

Figura 2. Comprimento de parte aérea, comprimento de raiz, fitomassa seca da parte aérea e fitomassa seca de raiz de plântulas de aveia branca, cultivares Barbarasul e Chiarasul, oriundas de sementes submetidas a concentrações de salinidade. Capão do Leão, 2012.
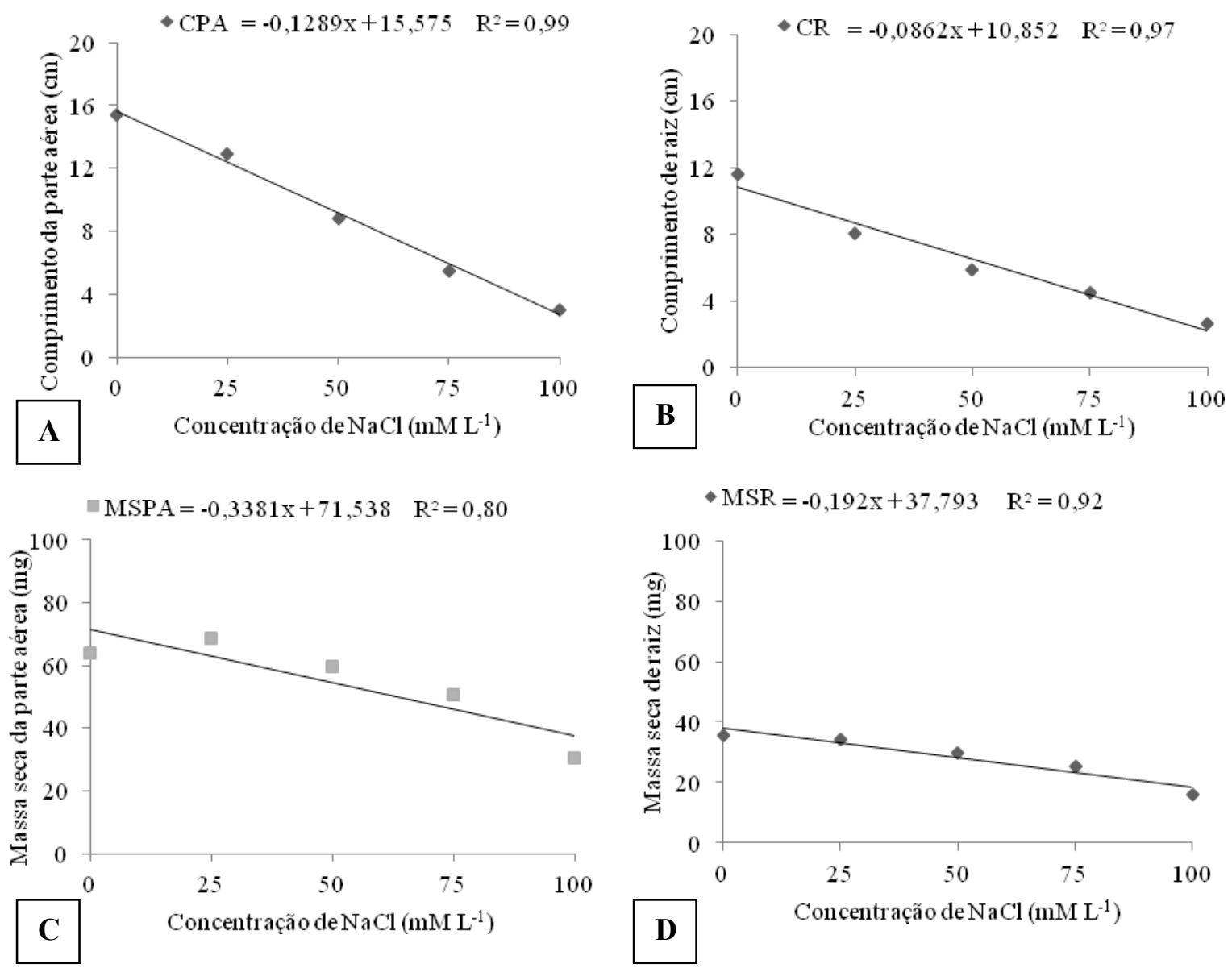

Fonte: Elaboração dos autores. 
O número de sementes mortas (Figura 1C) respondeu de forma não significativa ao aumento da concentração salina, no entanto, a porcentagem de plântulas anormais (Figura 1D) foi crescente para ambas as cultivares, onde até à dose de $50 \mathrm{mM}$ de $\mathrm{NaClL}^{-1}$ mostraram comportamento uniforme ao redor de $10 \%$, porém a partir da dose de $75 \mathrm{mM}$ de $\mathrm{NaClL}^{-1} \mathrm{o}$ aumento de plântulas anormais foi drástico para as duas cultivares.

$\mathrm{O}$ crescimento das plântulas, observado pelos comprimentos de parte aérea (Figura 2A) e raiz (Figura 2B), e fitomassa seca de parte aérea (Figura 2C) e raiz (Figura 2D), foi reduzido de forma linear com o aumento da concentração de $\mathrm{NaCl}$, independente da cultivar analisada. Verifica-se nas equações que para cada unidade de aumento na concentração de $\mathrm{NaCl}$ ocorreu uma redução na ordem de 0,13 e $0,08 \mathrm{~cm}$ de comprimento da parte aérea e de raiz, respectivamente, e uma redução de 0,34 e $0,19 \mathrm{mg}$ de fitomassa seca da parte aérea e de raiz, respectivamente. As curvas de tendência mostram que a ação do estresse salino é mais acentuada sobre a parte aérea do que o sistema radicular, tanto no comprimento quanto na fitomassa seca. Os resultados obtidos concordam com os encontrados por Daniel et al. (2011), em estudo realizado avaliando o desempenho de sementes de algodão colorido em diferentes níveis de salinidade, ao concluírem que o comprimento de raiz e parte aérea foram afetadas negativamente para todas as cultivares.

\section{Conclusão}

A germinação e o crescimento das plântulas de aveia branca das cultivares Barbarasul e Chiarasul são afetados negativamente com o aumento da concentração de $\mathrm{NaCl}$. Além disso, independente da cultivar, a resposta é mais acentuada sobre a parte aérea do que no sistema radicular. A concentração de $100 \mathrm{mM}$ de $\mathrm{NaCl} \mathrm{L}^{-1}$, praticamente impossibilita a germinação das sementes de ambas cultivares estudadas.

\section{Referências}

ALMEIDA, F.A.C.; GONÇALVES, N. J.M.; GOUVEIA, J. P. G.; CAVAlCANTE, L. F. Comportamento da germinação de sementes de arroz em meios salinos. Revista Brasileira de Produtos Agroindustriais, Campina Grande, v. 3, n. 1, p. 47-51, 2001.

ANDRÉO-SOUZA, Y.; PEREIRA, A. L.; SILVA, F. F. S.; RIBEIRO-REIS, R. C.; EVANGELISTA, M. R. V.; CASTRO, R. D.; DANTAS, B. F. Efeito da salinidade da germinação de sementes e no crescimento inicial de mudas de pinhão-manso. Revista Brasileira de Sementes, Lavras, v. 32, n. 2, p. 83-92, 2010.

ASHRAF, M. Biotechnological approach of improving plant salt tolerance usinf antioxidants asmarkers. Biotechnology Advances, New York, v. 27, n. 1, p. 84-93, 2009.

BRASIL. Ministério da Agricultura, Pecuária e Abastecimento. Regras para análise de sementes. Ministério da Agricultura, Pecuária e Abastecimento. Secretaria de Defesa Agropecuária. Brasília, DF: Mapa/ ACS, 2009. $395 \mathrm{p}$.

CAMPOS, I. S.; ASSUNÇÃO, M. V. Efeitos do cloreto de sódio na germinação e vigor de plântulas de arroz. Pesquisa Agropecuária Brasileira, Brasília, v. 25, n. 6, p. 837-843, 1990.

CECCON, G.; GRASSI FILHO, H.; BICUDO, S. J. Rendimento de grãos de aveia branca (Avena sativa L.) em densidades de plantas e doses de nitrogênio. Ciência Rural, Santa Maria, v. 34, n. 6, p. 1723-1729, 2004.

COMPANHIA NACIONAL DE ABASTECIMENTO CONAB. Central de informações agropecuárias: safra de grãos 2011/2012. 2012. Disponível em: <http://www. conab.gov.br/conabweb/download/safra $>$. Acesso em: 01 mar. 2012.

CONUS, L. A.; CARDOSO, P. C.; VENTUROSO, L. R.; SCALON, S. P. Q. Germinação de sementes e vigor de plântulas de milho submetidas ao estresse salino induzido por diferentes sais. Revista Brasileira de Sementes, Lavras, v. 31, n. 4, p. 67-74, 2009.

DANIEL, V. C.; SEVILHA, R. R.; SILVA, F. F.; ZONETTI, P. C. Germinação e crescimento de plântulas de algodão colorido sob condições de estresse salino. Revista em Agronegócios e Meio Ambiente, Maringá, v. 4, n. 2, p. 321-333, 2011.

DUARTE, L. G.; LOPES, N. F.; MORAES, D. M.; SILVA, R. N. Physiological quality of wheat seeds submitted to saline stress. Revista Brasileira de Sementes, Lavras, v. 28, n. 1, p. 122-126, 2006. 
FURTADO, R. F.; MANO, A. R. O.; ALVES, C. R.; FREITAS, S. M.; MEDEIROS FILHO, S. Efeito da salinidade na germinação de sementes de algodão. Revista Ciência Agronômica, Fortaleza, v. 38, n. 2, p. 224-227, 2007.

GORDIN, C.; MARQUES, R. F.; MASETTO, T. E.; SOUZA, L. C. F. Estresse salino na germinação de sementes e desenvolvimento de plântulas de niger (Guizotia abyssinica (L. F.) Cass.). Acta Botânica Brasílica, Feira de Santana, v. 26, n. 4, p. 966-972, 2012.

MACHADO, A. A.; CONCEIÇÃO, A. R. Sistema de análise estatística para windows. WinStat. versão 1.0. Pelotas: UFPel, 2003.

MARCOLIN, E.; ANGHINONI, I.; MACEDO, V. M.; GENRO JUNIOR, S. A.; VEZZANI, F. M. Salinidade da cultura do arroz no Rio Grande do Sul. Revista Lavoura Arrozeira, Porto Alegre, v. 53, p. 27-38, 2005.
NAKAGAWA, J. Testes de vigor baseados no desempenho das plântulas. In: KRZYZANOWSKI, F. C.; VIEIRA, R. D.; FRANÇA-NETO, J. B. Vigor de sementes: conceitos e testes. Londrina: ABRATES, 1999. cap. 2, p. 9-13.

SANTOS, V. L. M.; CALIL, A. C.; RUIZ, H. A.; ALVARENGA, E. M.; SANTOS, M. Efeito do estresse salino e hídrico na germinação e vigor de sementes de soja. Revista Brasileira de Sementes, Lavras, v. 14, n. 2, p. 189-194, 1992.

TUNES, L. M.; OLIVO, F.; BADINELLI, P. G.; CANTOS, A.; BARROS, A. C. S. A. Aspectos fisiológicos da toxicidez de ácidos orgânicos em sementes de aveia. Revista Biotemas, Florianópolis, v. 21, n. 4, p. 21-28, 2008. 